\title{
DESENVOLVIMENTO INSTITUCIONAL E O ENVOLVIMENTO DO SETOR PRIVADO NA PROVISÃO DE INFRA-ESTRUTURA*
}

\author{
Gisele Ferreira Tiryaki ${ }^{\S}$
}

\begin{abstract}
RESUMO
A participação do setor privado em projetos de infra-estrutura em países em desenvolvimento cresceu de forma significativa durante os anos de 1990, embora seja evidente o arrefecimento desta tendência desde a Crise Asiática em 1997. Investimentos em infra-estrutura envolvem um elevado volume de recursos, custos irreversíveis e riscos associados ao comportamento oportunista por parte do governo. Neste contexto, a instabilidade macroeconômica, política e institucional são obstáculos ao maior envolvimento de investidores privados em projetos de infra-estrutura. Utilizando-se da metodologia Generalized Method of Moments, este artigo apresenta evidência empírica de que o fluxo de recursos direcionados para projetos de infra-estrutura com a participação do setor privado é mais representativo em países com melhor arcabouço institucional.
\end{abstract}

Palavras-chave: investimento privado, infra-estrutura, instituições legais.

\begin{abstract}
Private participation in infrastructure grew significantly in developing countries during the 1990s, although a slowdown in investment activity has become evident since the Asian Crisis in 1997. Investment in infrastructure involves a significant volume of sunk costs on long-lived assets and risks associated with government's engagement in opportunistic holdup. In this context, macroeconomic, political and institutional instability constitute obstacles to a greater private sector envolvement in infraestructure projects. Using the Generalized Method of Moments methodology, this article presents empirical evidence that the flow of resources to infrastructure projects with private participation is greater in those coutries with a better institucional environment.
\end{abstract}

Keywords: private investment, infrastructure, legal institutions.

JEL classification: Q4, L33, G38.

* A autora agradece o suporte financeiro concedido pela Fundação de Amparo à Pesquisa do Estado da Bahia e as sugestões feitas pelos pareceristas anônimos.

$\S$ Professora/Pesquisadora da Universidade Salvador (UNIFACS). Endereço para contato: Rua Ponciano de Oliveira, 126, Rio Vermelho - Salvador - Bahia. CEP: 41.950-275. E-mail: gisele fsilva@unifacs.br.

Recebido em abril de 2007. Aceito para publicação em setembro de 2008. 


\section{INTRODUÇÃO}

Desde o início dos anos de 1990, observa-se uma participação ativa do setor privado na provisão de infra-estrutura de países em desenvolvimento. Implementados com o objetivo de melhorar a eficiência operacional, atrair recursos para setores de infra-estrutura em um contexto de restrições orçamentárias do setor público e, em alguns casos, possibilitar a elevação imediata de receitas para o governo através da venda de ativos, projetos de infra-estrutura envolvendo o setor privado já contabilizaram quase US\$1,3 bilhões em investimentos entre 1990 e 2006 (BANCO MUNDIAL, 2008a).

Não obstante, o fluxo de recursos decresceu de forma substancial desde a Crise Asiática em 1997, muito embora seja possível observar uma retomada dos investimentos a partir de 2003. Ainda de acordo com dados do Banco Mundial (2008a), o setor de energia foi o mais afetado dentre os setores de infra-estrutura: em 2006, investimentos em projetos de energia com participação privada representaram apenas $33 \%$ do montante investido em 1997. A queda dos investimentos em projetos no setor de telecomunicações e transportes também foi significativa, mas as atividades nesses setores vêm sendo retomadas desde 2003. O desempenho do setor de água e saneamento, por sua vez, não tem sido robusto, observando-se períodos de maior atividade quando ocorre a implementação de projetos isolados de grande porte.

O declínio no interesse do setor privado refletiu vários fatores, dentre os quais se ressaltam problemas na concepção dos programas delineados para atrair a participação do setor privado em infra-estrutura e a instabilidade macroeconômica, política e institucional observada em inúmeros países. A necessidade de renegociação de contratos de concessão tem sido bastante comum, como apontado por Harris (2003) e Guasch (2004), além de observarem-se também renacionalizações e o insucesso de vários projetos. Dos 3102 projetos com participação do setor privado que foram implementados em setores de infra-estrutura entre 1990 e 2004, 148 foram eventualmente cancelados, representando $5 \%$ do volume de investimentos no período (BANCO MUNDIAL, 2006).

Barreiras macroeconômicas, políticas e institucionais são relevantes em setores: (i) onde o volume de investimentos é elevado e com longo prazo de maturação; (ii) em que a especificidade dos ativos eleva o risco associado à perda futura no poder de barganha (obsolescing bargain), e (iii) em que presença de economias de escala e escopo implica maior intervenção regulatória do governo (e.g. manipulação de tarifas com objetivos não necessariamente associados à promoção da eficiência operacional).

Projetos em setores de infra-estrutura enquadram-se nas circunstâncias descritas acima, pois envolvem um elevado volume de custos irreversíveis e investimento em ativos com baixo valor em usos alternativos. Investidores privados negociando com entidades governamentais têm elevado poder de barganha ex ante, em face das restrições orçamentárias do governo. No entanto, tão logo o projeto entre em fase operacional, o governo tem incentivo de impor mudanças 
no contrato inicial, levando em consideração que o investidor continuará operando, desde que as receitas excedam os custos operacionais. Ou seja, na ausência de elementos que garantam a implementação futura de contratos pré-estabelecidos, o governo pode impor restrições nos preços, requerer investimentos adicionais e adotar outras estratégias que representem, em última instância, o comprometimento dos ativos e da rentabilidade inicialmente pactuada.

O nível e a qualidade dos serviços de infra-estrutura são determinantes para a produção e comercialização de bens e serviços, afetando a produtividade, custos e competitividade de uma economia e sendo, portanto, essencial para a promoção do crescimento econômico (ver REINIKKA e SVENSSON, 1999; CALDERON e SERVEN, 2003, e GUASCH, 2004). Identificar fatores de risco e delinear políticas que estimulem um maior envolvimento do setor privado em projetos de infra-estrutura é essencial, considerando-se, principalmente, as dificuldades orçamentárias enfrentadas pelo setor público de países em desenvolvimento.

A estabilidade política, o respeito aos preceitos legais, a eficácia no combate à corrupção, a proteção à propriedade, a qualidade da regulação e a eficiência das políticas governamentais são de fundamental importância para o investimento privado. Mais especificamente, em setores onde existe a presença de economias de escala e escopo, é essencial o estabelecimento de práticas regulatórias transparentes implementadas por entidades independentes e sujeitas ao escrutínio público (ver PARGAL, 2003).

Além dos aspectos de governança, a presença de um ambiente favorável para desenvolvimento de negócios também é determinante nas decisões de investimento do setor privado. As dificuldades enfrentadas com a legislação para abertura de um negócio e sua operação, com a rigidez no mercado de trabalho, com restrições no acesso ao crédito, com impostos elevados e com o cumprimento de contratos comerciais inibem o investimento privado. Ressalta-se ainda a importância da estabilidade macroeconômica, visto que investidores resistem em direcionar recursos para países de economia instável, principalmente quando o horizonte de investimento é prolongado e existe o risco de que o governo restrinja ajustes tarifários como forma de controle da inflação.

Este trabalho apresenta evidência empírica da relevância de aspectos institucionais para a participação do setor privado em projetos de infra-estrutura, particularmente nos setores de telecomunicações e energia. Vários trabalhos empíricos têm salientado a importância da qualidade institucional para diversos aspectos da economia, como para a promoção do crescimento econômico (ver, entre outros, HALL e JONES, 1999, e EICHER et al., 2006), para a redução da volatilidade macroeconômica (ACEMOGLU et al., 2003) e para o crescimento industrial (GRIGORIAN e MARTINEZ, 2000).

A conexão entre qualidade institucional e performance de setores de infra-estrutura também já foi analisada, mas com metodologia ou foco diferenciado do apresentado aqui. Pargal (2003), por exemplo, salientou a importância da independência e credibilidade do regulador para o clima de investimento em infra-estrutura, mas sua análise incluiu dados de apenas nove 
países na América Latina. Cubbin e Stern (2005), por sua vez, estabeleceram a conexão entre aspectos institucionais e a eficiência na provisão de eletricidade em países em desenvolvimento, mas não estabeleceram a conexão com o fluxo de investimento envolvendo o setor privado. Bergara et al. (1997) e Henisz (2002) limitaram-se a analisar a importância de instituições políticas sólidas para a provisão de capacidade de geração de energia, não levando em consideração os demais indicadores de governança e variáveis representando ambiente para negócios, enquanto Jensen e Blanc-Brude (2006) apontaram para o aumento na probabilidade de envolvimento do setor privado no setor de água e saneamento na presença de indicadores de governança mais robustos.

A análise que mais se assemelha à conduzida aqui foi elaborada por Banerjee et al. (2006). No entanto, os resultados apresentados por esses autores foram distintos dos obtidos no presente trabalho, provavelmente em virtude do uso de amostra com número menor de países e metodologia econométrica distinta. ${ }^{1}$ A proteção aos direitos de propriedade e qualidade da burocracia são os principais determinantes de investimentos em infra-estrutura com participação do setor privado de acordo com os referidos autores, que apontam também para o fato de que países com corrupção elevada vêm atraindo um maior fluxo de investimento em infra-estrutura (resultado não consubstanciado com a evidência empírica apresentada a seguir).

Utilizando-se de diversos indicadores de governança e de qualidade no ambiente de negócios e de variáveis controlando para a importância de outros fatores determinantes do fluxo de investimento, os resultados discutidos a seguir indicam que o desenvolvimento institucional estimula um maior envolvimento do setor privado em projetos de infra-estrutura. A possibilidade de que aspectos de governança e de ambiente de negócios sejam variáveis endógenas implica a necessidade de uso de variáveis instrumentais. Assim, utilizando dados em cross-section e em painel, a análise econométrica foi conduzida implementando-se a metodologia Generalized Method of Moments (GMM).

O artigo está organizado da seguinte forma: a Seção 2 analisa de forma sucinta como tem sido o envolvimento do setor privado em setores de infra-estrutura desde 1990. A terceira seção descreve as variáveis utilizadas, enquanto a quarta seção discute a metodologia empregada. A quinta seção apresenta os resultados obtidos e a avalia a robustez da análise econométrica. A última seção apresenta as conclusões.

1 Esses autores utilizaram o método dos mínimos quadrados ordinários e não incluíram o nível defasado da variável dependente como variável explicativa. Ignoraram, assim, a possibilidade de endogeneidade das variáveis explicativas e autocorrelação dos resíduos. 


\section{O SETOR PRIVADO E A PROVISÃO DE INFRA-ESTRUTURA EM PAÍSES EM DESEN- VOLVIMENTO: UMA BREVE DESCRIÇÃO}

O reconhecimento da necessidade de investimentos em infra-estrutura para a viabilização do crescimento econômico tem levado inúmeros países a atrair a participação do setor privado. Para os países em desenvolvimento, mais especificamente, a atuação do setor privado torna-se fundamental, tendo em vista as dificuldades financeiras enfrentadas pelo setor público.

Os dados estatísticos descritos a seguir e utilizados nos testes econométricos foram obtidos do PPI Database (BANCO MUNDIAL, 2006 e 2008a). ${ }^{2}$ Neste banco de dados, os valores de investimento disponibilizados não se referem exclusivamente a investimentos realizados pelo setor privado. No caso de concessões e de projetos do tipo greenfield, os valores refletem o total de recursos a serem direcionados na implementação de determinado projeto e que estão com financiamento garantido, através de recursos próprios ou de terceiros (se o projeto envolver parceria público-privada, o total a ser investido é registrado, não somente o comprometimento do setor privado). No caso de privatizações, quando o controle acionário permanece com o poder público, contabiliza-se somente a venda inicial das ações, enquanto que, nos casos em que o setor privado assume o controle acionário e gerenciamento da empresa, inclui-se não somente o valor pago pelas ações, mas o investimento anual subseqüente. ${ }^{3}$ É importante salientar, contudo, que apesar de possíveis distorções associadas à heterogeneidade dos dados, as variações no volume de investimento total refletem, em última instância, flutuações na disposição dos investidores privados para participarem em projetos de infra-estrutura nos países em desenvolvimento.

Entre 1990 e 2006, 138 países em desenvolvimento promoveram a participação do setor privado na provisão de infra-estrutura, com destaque para o Brasil, China, Argentina, México, Índia e Malásia, para onde metade dos investimentos em infra-estrutura, com o envolvimento do setor privado, foram direcionados.

O setor de telecomunicações tem apresentando posição de destaque desde 1998, sendo o menos afetado pelo declínio em interesse do setor privado por projetos de infra-estrutura em países em desenvolvimento que se observa desde a Crise Asiática. A redução no volume de investimentos ocorrida entre 2000 e 2003 refletiu, em sua maior parte, o final do período de privatizações e concessões de spectrum mais representativas. De acordo com Izaguirre (2005), o fluxo de investimento para a compra de ativos governamentais vem declinando desde 2000, mas os recursos direcionados para expansão e melhoria na qualidade de serviços têm apresentado tendência ascendente desde 1990.

2 Os dados desagregados por segmentos e que são descritos nessa seção somente estão disponíveis para o período entre 1990 e 2004, mas foi possível obter os dados setoriais para 2005 e 2006 do banco de dados World Development Indicators (BANCO MUNDIAL, 2008a).

3 Para maiores detalhes sobre a metodologia adotada, ver http://ppi.worldbank.org. 
Destacaram-se os projetos realizados nos segmentos de telefonia móvel, integrados ou não aos segmentos de telefonia fixa e de longa distância (ver Tabela 1). Em termos regionais, a América Latina absorveu cerca de $40 \%$ dos investimentos em projetos de telecomunicações implementados entre 1990 e 2006 (com destaque para Argentina, Brasil e México), enquanto países do leste Europeu e da Ásia Central lideraram em termos de número de projetos.

Mais de $40 \%$ dos projetos com participação do setor privado que foram realizados em países em desenvolvimento envolveram a geração, transmissão e distribuição de eletricidade e o transporte e distribuição de gás natural. Dentre os fatores que contribuíram para a posição de destaque deste setor, ressaltam-se as inovações tecnológicas que: (i) reduziram a escala eficiente mínima de plantas geradoras de eletricidade, (ii) minimizaram os custos de transação e (iii) permitiram uma maior eficiência na utilização da rede. A América Latina liderou não somente em termos de número de projetos, mas também em volume de investimentos: mais de $30 \%$ dos projetos no setor de energia foram realizados na região, que absorveu $45 \%$ do fluxo de investimentos para o setor. Como se observa na Tabela 1, o segmento de eletricidade captou quase a totalidade dos investimentos, refletindo o estágio inicial de desenvolvimento do segmento de gás natural na maioria dos países em desenvolvimento.

Tabela 1 - Participação privada em infra-estrutura por segmentos, 1990 - 2004

\begin{tabular}{ll|cccc}
\hline & & \multicolumn{3}{|c}{ AMOSTRA } \\
& Segmento & N. Projetos & \% do Total & US\$ Bilhões & \% do Total \\
\hline Telecomunicações & Móvel $^{*}$ & 454 & 64,7 & 341.1 & 74.7 \\
& Fixa e/ou Longa Distância & 248 & 35,3 & 115.5 & 25.3 \\
Total do Setor & & 702 & 100 & 456,6 & 100 \\
\hline Energia & Eletricidade & 981 & 81,5 & 266,6 & 83,7 \\
& Gás Natural & 223 & 18,5 & 51,8 & 16,3 \\
Total do Setor & & 1204 & 100 & 318,5 & 100 \\
\hline Transporte & Rodovias & 352 & 47,4 & 68,2 & 52,7 \\
& Ferrovias & 82 & 11,1 & 27 & 20,8 \\
& Portos & 218 & 29,4 & 22,8 & 17,6 \\
Total do Setor & Aeroportos & 90 & 12,1 & 11,4 & 8,8 \\
\hline Água \& Saneamento & & 742 & 100 & 129,5 & 100 \\
& Água & 97 & 31,7 & 15,5 & 34,8 \\
& Saneamento & 61 & 19,9 & 2,7 & 6,1 \\
Total do Setor & Integrada & 148 & 48,4 & 26,3 & 59,1 \\
\hline Total & & 306 & 100 & 44,5 & 100 \\
\hline
\end{tabular}

Nota: * Foram incluídos neste segmento projetos de telefonia móvel em combinação ou não com telefonia fixa e de longa distância; os dados estatísticos apresentados excluem os projetos que foram cancelados.

Fonte: PPI Database (BANCO MUNDIAL, 2006). 
A participação privada em infra-estrutura de transportes concentrou-se no segmento de rodovias pedagiadas, que absorveu mais da metade dos investimentos direcionados para o setor. Projetos de infra-estrutura portuária também são comuns, mas vêm envolvendo, normalmente, menor aporte de capital do que os projetos de ampliação e construção de rodovias e ferrovias.

Já no setor de água e saneamento, o fluxo de investimento foi direcionado principalmente para projetos envolvendo a infra-estrutura integrada desses dois segmentos. A participação do setor privado no setor tem sido inconstante, com períodos em que investimentos volumosos são acordados, seguidos por períodos de fraco desempenho. A maior dificuldade em se atrair investimento privado para o setor é a resistência política em se elevar tarifas a níveis que permitam cobrir os custos do serviço, o que tem levado à renegociação de muitos contratos e ao questionamento da viabilidade de se engajar o setor privado na provisão de água e saneamento (ver IZAGUIRRE, 2005a).

No Brasil, mais da metade dos investimentos em projetos de infra-estrutura com a participação do setor privado foram direcionados para o setor de energia e em torno de um terço dos recursos fluíram para o setor de telecomunicações. O engajamento do setor privado em projetos nos setores de transportes e de água e saneamento foi menos expressivo, sendo resultado, principalmente, de iniciativas isoladas de governos estaduais e municipais.

Os esperados ganhos em eficiência com a participação do setor privado nem sempre têm sido observados e, mais recentemente, a opinião pública tem demonstrado insatisfação com o desempenho dos agentes privados. Enquanto, em 1998, uma pesquisa realizada pelo Latinobarómetro indicava que apenas $45 \%$ dos entrevistados estavam insatisfeitos com a privatização (HARRIS, 2003), em 2006, 65\% dos entrevistados pelo mesmo instituto declaravam-se descontentes com a privatização de serviços públicos estatais (THE ECONOMIST, 2007).

Vários fatores vêm contribuindo para esta performance desfavorável, como, por exemplo, as dificuldades de transição de um modelo de gerenciamento estatal de empresas para um modelo privado, a incapacidade de alguns governos de gerenciar as reformas setoriais e promover a estabilidade econômica e a existência de comportamento oportunístico tanto por parte do governo como por parte do setor privado. Não obstante as dificuldades enfrentadas e o desempenho desfavorável em alguns casos, a evidência empírica sugere que o engajamento do setor privado na provisão de infra-estrutura tem sido associado a ganhos em termos de eficiência, qualidade e expansão na oferta de serviços. Harris (2003), por exemplo, apresenta uma revisão dos resultados de vários trabalhos empíricos que apontam para ganhos de eficiência com a participação do setor privado. Anuatti Neto et al. (2005), por sua vez, apontam para os resultados positivos da experiência brasileira com privatizações (a análise inclui empresas no setor de distribuição de energia e telecomunicações). 


\section{Dados estatísticos}

Expressos originalmente em dólares americanos e em termos nominais, os investimentos anuais direcionados aos setores de telecomunicações, energia, transporte, água e saneamento de países em desenvolvimento foram convertidos para valores reais utilizando-se o ano 2005 como base (ver Apêndice 1 para a lista de países incluídos em cada teste econométrico). Na análise em cross-section, calculou-se a mediana do investimento real per capita entre 1990 e $2006 .{ }^{4}$ Já na análise de dados em painel, em virtude de limitações na obtenção de dados anuais para as variáveis de governança, utilizou-se o valor do investimento anual per capita entre 1996 e $2006{ }^{5}$

O uso de valores de investimento per capita possibilita fazer uma comparação mais adequada da extensão da participação privada em infra-estrutura entre os diversos países em desenvolvimento, pois quanto maior a população de um país, maior a necessidade de investimentos em serviços de infra-estrutura. Assim, o uso do volume de investimentos em termos globais distorceria os resultados dos testes econométricos discutidos a seguir. Inclusive, uma análise preliminar dos dados estatísticos revela que os países com maiores volumes absolutos de investimento em projetos de infra-estrutura com a participação privada não são os mesmos que apresentam maiores valores de investimento per capita. Somente a Argentina e Malásia figuram na classificação dos dez países com maior investimento em projetos de infra-estrutura em termos absolutos ou per capita.

Os testes com dados em cross-section utilizaram três variáveis dependentes distintas: o investimento per capita em todos os setores de infra-estrutura (PPI), em telecomunicações (PPITEL) e em energia (PPIEN). Não foram utilizados os dados estatísticos de transporte e água e saneamento separadamente em virtude do reduzido número de países que já implementaram projetos nestes setores. $\mathrm{Na}$ análise de dados em painel, utilizou-se apenas PPI, visto que, para muitos países, quando se desagrega o investimento por setor, os investimentos anuais são intermitentes, até porque os valores disponíveis no banco de dados referem-se, com freqüência, a comprometimento de investimento ao longo da duração de um projeto. ${ }^{6}$

A escolha dos países incluídos na amostra foi feita com base no fluxo de investimentos para projetos com participação privada. A seleção foi feita com base no ano de início do engajamento mais representativo do setor privado. Assim, foram selecionados aqueles países onde há

4 Os testes descritos a seguir também foram realizados utilizando-se o total acumulado do investimento entre 1990 e 2006 dividido pela população média no período. Os resultados obtidos são semelhantes aos descritos a seguir e podem ser obtidos da autora caso solicitados.

5 O uso de dados estatísticos em painel reduz o número viável de países a serem incluídos nos testes econométricos, porque raros são os casos em que há evidência de investimento continuado em projetos de infra-estrutura com participação privada. Isto ocorre porque, como apontado anteriormente, o volume de investimentos disponível no PPI Database reflete, em muitos casos, investimento a ser realizado por um horizonte de tempo longo, ao invés de investimento anual já realizado. Assim, a redução do período de tempo a ser analisado possibilita a inclusão de um maior número de países, pois, para a maior parte dos países, o maior fluxo de investimento privado em projetos de infra-estrutura concentrou-se na segunda metade dos anos de 1990.

6 Isto é particularmente comum nos setores de energia, água e saneamento e transportes, onde ocorre o predomínio dos contratos de concessão de longo prazo. 
evidência de participação do setor privado em projetos de infra-estrutura pelo menos a partir de 1998, ano mediano da amostra. Esta estratégia foi utilizada para evitar distorções causadas pela inclusão de países em que a participação do setor privado foi mais tardia.

\subsection{Indicadores de governança e de ambiente de negócios}

Existe consenso que a existência de um arcabouço regulatório robusto, a estabilidade política e macroeconômica e a credibilidade das políticas governamentais reduzem o risco de expropriação formal e informal e estimulam o investimento privado. Vários indicadores foram utilizados para indicar a qualidade institucional e o ambiente de negócios de um país. ${ }^{8}$

As variáveis que representam aspectos de governança foram obtidas no banco de dados Governance Indicators (BANCO MUNDIAL, 2007). Esses indicadores foram calculados com base em informações sobre as percepções de agentes econômicos sobre governança, coletadas através de enquetes realizadas com representantes de unidades familiares e empresas e com especialistas envolvidos com agências de avaliação de riscos, com organizações do terceiro setor, entidades multilaterais e agências governamentais (ver KAUFMANN et al., 2008). Esses autores defendem o uso de dados subjetivos ou baseados nas percepções dos agentes por três razões: (i) as ações dos agentes são motivadas por suas impressões e visão de como as instituições em determinado país operam (por exemplo, uma empresa decide investir em determinado país a partir de suas percepções acerca das condições de investimento e de políticas governamentais); (ii) inexistem informações alternativas a serem utilizadas para quantificar determinados aspectos de governança (medir o nível de corrupção de outra forma, por exemplo, é difícil, pois corrupção, normalmente, não deixa evidências concretas), e (iii) mesmo quando existem medidas objetivas para se estimar o nível de governança, tais medidas são normalmente delineadas com base na existência de determinadas regulamentações, mas é comum ocorrerem situações em que as regras do jogo não seguem o que está estabelecido por leis.

Os indicadores são calculados utilizando-se a metodologia conhecida como modelo de componentes não-observáveis, estimando-se os indicadores agregados com base em medidas individuais de percepções sobre governança (os indicadores são médias ponderadas dessas informações, sendo que os pesos refletem a precisão das fontes de dados individuais). A última versão do banco de dados conta com dados de 212 países coletados de 35 fontes de informações distintas para as seguintes variáveis: ${ }^{9}$

7 O atraso no engajamento do setor privado em um país implicaria menores volumes de investimento, sem que haja, necessariamente, uma conexão com indicadores de governança menos robustos.

8 Na análise em cross-section, calculou-se a mediana dos indicadores de governança entre 1996 e 2006 , já que não há dados disponíveis para esses indicadores em períodos anteriores.

9 As variáveis de governança representam o ranking percentil do país, refletindo o porcentual de países que estão colocados em posição inferior ao país em questão. Ou seja, um valor elevado para determinado indicador significa que o país ocupa uma melhor colocação na classificação dos países em determinado aspecto de governança. Assim, se um indicador aumenta, por exemplo, de $57 \%$ para $58 \%$, isso significa que as percepções dos agentes econômicos sobre aquele aspecto institucional foram alteradas de forma que, se antes existiam 121 países em condição inferior ao país em questão, agora existem 123, de um total de 212 países. Os indicadores, portanto, indicam as mudanças na posição relativa dos países. 
- Participação Civil (CIVIL): este indicador mede as percepções dos indivíduos sobre sua possibilidade de participar no processo de seleção de representantes para o governo e sobre a liberdade de expressão, associação e de imprensa.

- Tradição Legal (LEIS): essa variável mede a tradição de cada país no que se refere a preceitos legais e de ordem; ou seja, mede o nível de confiança e respeito que os indivíduos têm em relação à regulação. Indica-se, por exemplo, a qualidade dos mecanismos que permitem que: (i) os contratos sejam cumpridos; (ii) os direitos de propriedade sejam garantidos; (iii) a polícia e a poder judiciário sejam eficazes, e (iv) a probabilidade de crime e violência seja reduzida;

- Qualidade da regulação (REGQUAL): esse indicador reflete a percepção dos agentes econômicos sobre a habilidade do governo em delinear e implementar medidas que viabilizem e estimulem o desenvolvimento do setor privado;

- Controle da Corrupção (CORRUP): esta variável é uma estimativa da existência de mecanismos que limitem a utilização do poder político para ganho privado (inclui-se, aqui, corrupção ativa e passiva e captura do governo pela elite ou interesses privados);

- Estabilidade Política (ESTPOL): mede a percepção que existe entre agentes econômicos da probabilidade que um governo seja desestabilizado ou destituído, possivelmente de maneira inconstitucional ou por formas violentas, e

- Eficiência do Governo (GOVEFIC): medem-se, aqui, as percepções sobre a qualidade na provisão de serviços públicos, qualidade da burocracia, credibilidade na execução de políticas delineadas, competência dos servidores públicos e nível de independência destes para com pressões políticas.

Quanto à qualidade do ambiente para realização de negócios, foram utilizadas duas variáveis, sendo que a primeira teve por fonte o Doing Business Database (BANCO MUNDIAL, 2008b), e a segunda foi obtida do World Economic Outlook Database (FUNDO MONETÁRIO INTERNACIONAL, 2007):

- Facilidade na implementação e operação de negócios (FACINEG): este índice representa a ordenação de 155 países em termos de facilidade na realização de negócios. Primeiro, calculou-se o percentil de cada país para cada um dos seguintes aspectos: custos associados à abertura de negócios, dificuldades encontradas para obtenção de licenças de operação e para o registro de propriedade, rigidez da legislação trabalhista, dificuldades no acesso ao crédito, existência de mecanismos de proteção aos investidores minoritários, peso da carga tributária, existência de limitações ao comércio internacional, dificuldades encontradas para o cumprimento de contratos e custos associados ao encerramento de negócios. Calculou-se a média simples com os valores do percentil de cada aspecto e classificou-se os países entre 1 e 155, com números menores indicando melhores condições no ambiente de negócios. Calculou-se, então, a mediana desse indicador entre 2004 e 2006, período em que existem dados disponíveis sobre o indicador. 
- Estabilidade macroeconômica (INFMED): investidores resistem em direcionar recursos para países de economia instável, principalmente quando o horizonte de investimento é prolongado. No setor de energia, particularmente, existe um agravante adicional, pois governos de países com taxas de inflação elevadas freqüentemente manipulam preços de insumos energéticos, como forma de conter altas gerais de preços. Calculou-se, então, a taxa mediana de inflação entre 1990 e 2006.

A importância dos aspectos de governança e de ambiente propício para negócios é ilustrada com o exemplo do Brasil. A Tabela 2 mostra que o País apresentou, no período em análise, indicadores institucionais favoráveis, precisando melhorar sua performance principalmente no que se refere à facilidade na implementação e operação de negócios.

Tabela 2 - Indicadores de governança e ambiente de negócios no Brasil: 1990 - 2006

\begin{tabular}{lccccc}
\hline & \multicolumn{5}{c}{ Amostra $^{1}$} \\
\hline Indicadores de Governança & Brasil & Média & Mediana & Máximo & Mínimo \\
\hline CIVIL & 58,4 & 42,8 & 42,1 & 89,0 & 0,5 \\
LEIS & 41,8 & 39,1 & 39,1 & 86,2 & 3,6 \\
REGQUAL & 55,7 & 43,0 & 41,0 & 91,5 & 1,5 \\
CORRUP & 58,8 & 39,7 & 39,8 & 89,6 & 3,2 \\
ESTPOL & 44,8 & 38,5 & 36,8 & 83,5 & 2,7 \\
GOVEFIC & 54,8 & 43,2 & 40,8 & 88,2 & 6,0 \\
\hline Indicadores de Ambiente de Negócios & & & & & \\
\hline FACINEG & 119 & 92,9 & 94,0 & 171,0 & 15,0 \\
INFMED & 8,4 & 11,2 & 7,4 & 64,9 & 0,5 \\
\hline
\end{tabular}

Nota: ${ }^{1}$ A amostra compreende 99 países em desenvolvimento, conforme Apêndice 1.

O Brasil apresentou fluxo de investimentos acima da média em quase todos os setores de infra-estrutura e o seu desempenho poderia ter sido ainda mais positivo, se o ambiente de negócios do País fosse menos inóspito. Por exemplo, o Brasil, que ocupa a $1^{\text {a }}$ colocação entre os países de renda média e baixa, em termos de volume de recursos investidos em projetos de infra-estrutura com a participação do setor privado entre 1990 e 2006, situou-se apenas na $17^{\mathrm{a}}$ colocação quando consideramos a mediana do investimento per capita no período.

A Tabela 3 delineia os coeficientes de correlação em pares entre os indicadores de governança e de ambiente de negócios e PPI, evidenciando a relevância do desenvolvimento institucional para o investimento privado em infra-estrutura. ${ }^{10}$ Observa-se que todos os indicadores de governança são significativamente correlacionados com o investimento global per capita em

10 As matrizes de correlação entre os indicadores de qualidade institucional e o investimento setorial per capita estão disponíveis caso sejam solicitados. 
infra-estrutura. FACINEG também é correlacionados com PPI, mas com menor intensidade, enquanto que INFMEDIA não apresenta correlação de relevância. ${ }^{11}$

Tabela 3 - Instituições e investimento em infra-estrutura: correlação em pares

\begin{tabular}{|c|c|c|c|c|c|c|c|c|c|}
\hline & PPI & LEIS & REGQUAL & CORRUP & ESTPOL & CIVIL & GOVEFIC & FACINEG & INFMEDIA \\
\hline PPI & 1,000 & & & & & & & & \\
\hline LEIS & 0,599 & 1,000 & & & & & & & \\
\hline REGQUAL & 0,579 & 0,825 & 1,000 & & & & & & \\
\hline CORRUP & 0,606 & 0,923 & 0,838 & 1,000 & & & & & \\
\hline ESTPOL & 0,600 & 0,778 & 0,643 & 0,748 & 1,000 & & & & \\
\hline CIVIL & 0,569 & 0,767 & 0,805 & 0,763 & 0,720 & 1,000 & & & \\
\hline GOVEFIC & 0,642 & 0,906 & 0,898 & 0,911 & 0,708 & 0,790 & 1,000 & & \\
\hline FACINEG & $-0,449$ & $-0,594$ & $-0,659$ & $-0,549$ & $-0,509$ & $-0,563$ & $-0,674$ & 1,000 & \\
\hline INFMEDIA & $-0,270$ & $-0,261$ & $-0,276$ & $-0,308$ & $-0,128$ & $-0,221$ & $-0,287$ & 0,022 & 1,000 \\
\hline
\end{tabular}

Como os indicadores de governança possuem elevados índices de correlação entre si, a inclusão simultânea desses indicadores pode levar a problemas associados com multicolinearidade: as variáveis deixam de ser estatisticamente significantes, mas o ajuste da regressão é melhor. A solução padrão é introduzir uma variável que represente a importância conjunta dos indicadores de qualidade institucional relevantes para o investimento per capita em infra-estrutura com a participação do setor privado. Criou-se, assim, um indicador sintético, GOVERNANCA, que é a média aritmética de LEIS, REGQUAL, CORRUP, ESTPOL, CIVIL e GOVEFIC.

\subsection{Variáveis instrumentais}

A possibilidade de que os indicadores de governança e FACINEG sejam variáveis endógenas requer a utilização de variáveis instrumentais. A qualidade institucional pode ser relacionada com a origem legal de cada país, que é uma variável exógena, pois o sistema legal da maioria dos países foi estabelecido através da colonização ou por cópia direta ou mais subjetiva.

Vários estudos têm demonstrado a importância da origem legal na forma em que as instituições de um país são delineadas (ver LA PORTA et al., 1998 e 1999; DJANKOV et al., 2002; BECK et al., 2002). Argumenta-se que as tradições legais diferem na prioridade dada à propriedade privada e aos direitos do Estado e na sua capacidade de se adaptar eficientemente a mudanças, impactando, assim, na eficiência com que contratos pactuados são respeitados.

11 Diferentemente dos resultados apresentados por Banerjee, Oetzel e Ranganathan (2006), um maior nível de controle da corrupção é associado com um maior fluxo de investimento per capita para projetos de infra-estrutura com participação do setor privado. 
De acordo com Beck e Levine (2002), por exemplo, o código Napoleônico, que influenciou o sistema legal de vários países, foi delineado com alto grau de formalismo e rigidez, deixando pouco espaço para que o judiciário deliberasse publicamente sobre quais leis, costumes e experiências passadas seriam relevantes para um contexto em evolução. ${ }^{12}$ Já no código civil de origem alemã e no direito consuetudinário inglês, o judiciário possui maior escopo de atuação, sendo menos limitado pelo formalismo e possuindo uma visão mais favorável a reformas progressistas. Muito embora o sistema legal da maioria dos países venha se modificando ao longo dos anos, os principais elementos da origem legal foram mantidos.

Informações sobre a origem legal dos países da amostra utilizada aqui foram obtidas em CIA (2007). Criaram-se quatro variáveis dummy, indicando se a origem legal de cada país é francesa, inglesa, germânica ou outra (LGFRAN, LGING, LGGER e LGOUTROS). A origem legal francesa foi atribuída às antigas colônias francesas e àquelas pertencentes aos países conquistados por Napoleão (e.g. colônias de Portugal e Espanha). Os países de origem legal inglesa compreendem aqueles que utilizam a Common Law (direito consuetudinário) da Inglaterra: as antigas colônias britânicas e os países que fazem parte da Commonwealth. A origem legal germânica, por sua vez, foi atribuída aos países da Europa central onde o sistema legal alemão foi adotado (e.g. Hungria, Letônia e Polônia). Para aqueles países que possuem a origem legal socialista ou islâmica, classificou-se a origem legal como LGOUTROS.

As estimativas indicam que LGGER, LFRAN e LGOUTROS apresentam maior correlação com GOVERNANCA. O teste de Wald para a hipótese $H_{0}: \pi=0$, onde $\pi$ é o vetor de coeficientes estimados para LGGER, LGFRAN e LGOUTROS da equação de regressão abaixo, indica que os instrumentos são robustos. ${ }^{13}$

$$
\text { GOVERNANCA }=\alpha_{1}+\alpha_{2} \text { LGGER }+\alpha_{3} \text { LGFRAN }+\alpha_{4} \text { LGOUTROS }+\varepsilon
$$

Essas variáveis dummy foram utilizadas apenas na análise em cross-section, não sendo possível utilizá-las como instrumentos na análise com dados longitudinais. Na análise em painel, foram utilizadas as variáveis defasadas como instrumentos, conforme descrito na subseção 3.3 a seguir.

\subsection{Variáveis de controle}

Foram incluídas nas análises de regressão variáveis representando outros fatores que determinam os investimentos em cada setor de infra-estrutura. Em todos os testes, independentemente se realizados com investimentos globais per capita em infra-estrutura ou com investimentos setoriais per capita, adicionou-se o logaritmo da renda per capita de cada país - em US\$,

12 Djankov et al. (2002) apontam também que testes empíricos indicam que tal formalismo é associado a maiores prazos nos procedimentos judiciários, menor consistência, menor honestidade, menor justeza nas decisões judiciais e maior corrupção.

13 Caso solicitado, essas estimativas podem ser disponibilizadas pela autora. O teste revelou uma Estatítisca de Wald igual a 18,656 , o que implica a rejeição de $H_{0}$ a um nível de significância de $5 \%$ (valor da tabela para $\chi_{0,05}^{2}(3)$ é 7,815). 
ano base 2005 - expressa em termos de paridade de poder de compra (RENDA), o porcentual da população de cada país que mora na zona urbana (URBANA) e a taxa de analfabetismo (TXANALF). ${ }^{14}$

A variável RENDA foi utilizada porque se espera que países com renda elevada atraiam mais o interesse do setor privado em participar de projetos de infra-estrutura, visto que a demanda por tais serviços tende a ser mais significativa, elevando, assim, a expectativa de ganhos. Por exemplo, em países com renda mais elevada, a população tende a fazer maior uso de eletricidade e gás natural (ver, por exemplo, BERGARA et al., 1997). Observa-se também maior demanda por serviços de telefonia e por serviços de água e saneamento eficientes, e a presença de um comércio mais dinâmico, implicando uma necessidade crescente de infra-estrutura de transportes. Espera-se, assim, que RENDA seja positivamente relacionada com o volume de investimento per capita em infra-estrutura com participação do setor privado.

Espera-se também que países em que o grau de urbanização é mais elevado haja uma maior demanda por investimentos na provisão de serviços básicos de infra-estrutura, particularmente em água e saneamento e transporte público. Essa maior demanda por serviços permite o equilíbrio econômico dos projetos, atraindo o investimento privado (ver BEATO e VIVES, 2003). Desta forma, o investimento per capita em projetos de infra-estrutura que envolvem o setor privado deve ser maior em países com maior grau de urbanização, ceteris paribus.

Em relação à taxa de analfabetismo, essa variável foi adicionada porque estudos empíricos apontam para a importância do capital humano de um país como estímulo para a atração de investimentos privados, particularmente de origem estrangeira (ver, por exemplo, GHURA e GOODWIN, 2000; KIRKPATRICK et al., 2006). ${ }^{15}$ A existência de mão-de-obra qualificada é importante, particularmente para indústrias intensivas em capital, avançadas tecnologicamente e que envolvem processos de produção flexíveis, sendo, por conseguinte, particularmente relevante para os setores de energia e telecomunicações. Portanto, espera-se um maior fluxo de investimento privado para projetos de infra-estrutura implementados em países com uma mãode-obra qualificada.

Nas regressões em que o investimento per capita em telecomunicações representa a variável dependente, adicionou-se também o número de assinantes de telefonia fixa e móvel por cada 100 pessoas da população do ano em que se iniciou o envolvimento do setor privado em projetos de telecomunicações em cada país (LFIXASCEL). De acordo com Banerjee et al. (2006), a qualidade do investimento público já realizado contribui para estimular o investimento privado. Portanto, espera-se um maior interesse do setor privado em participar de projetos de telecomunicação em países que possuem uma rede de telefonia já representativa.

14 Na análise em cross-section, calculou-se a mediana dessas variáveis no período entre 1990 e 2006 . A não ser que se indique alternativamente, as variáveis de controle relacionadas nessa seção foram obtidas do Banco Mundial (2008a).

15 Utilizou-se, também, o porcentual da população com nível secundário e os resultados obtidos são semelhantes aos descritos a seguir. Estes resultados serão disponibilizados pela autora, caso sejam solicitados. 
Quando a variável dependente foi PPIEN, incluiu-se uma variável de controle adicional: a razão entre a unidade de utilização de energia (kg de óleo equivalente) per capita (EFENERG), para o ano inicial do envolvimento do setor privado em projetos de energia em cada país. Espera-se que investimentos para projetos de energia com participação do setor privado fluam de forma mais representativa para países em que a utilização de energia por habitante é reduzida, pois, nesses casos, a perspectiva de crescimento da demanda por energia é maior, elevando a expectativa de ganhos para o investidor. ${ }^{16}$

\section{Metodologia}

A análise econométrica teve por objetivo testar a hipótese de que países com instituições robustas e com um ambiente para negócios estável experimentam um maior fluxo de investimento em projetos de infra-estrutura com a participação do setor privado. Para isso, foi utilizada uma amostra de 99 países em desenvolvimento durante o período compreendido entre 1990 e 2006, implementando-se análises em cross-section e em painel. ${ }^{17}$

\subsection{Análise em cross-section}

A análise de dados em cross-section permite determinar se mudanças no nível dos indicadores de governança contribuem para explicar variações no nível de investimento per capita em projetos de infra-estrutura envolvendo o setor privado entre vários países. Esta análise permite o uso de um número mais elevado de países e permite estimar as equações utilizando, além do investimento global em infra-estrutura com participação do setor privado, o investimento setorial em energia e telecomunicações, através do cálculo da mediana das variáveis entre 1990 e $2006 .^{18}$

A metodologia econométrica utilizada foi o Generalized Method of Moments (GMM). Na presença de heterocedasticidade, que é comum em análise de regressão com dados em crosssection, GMM é mais eficiente do que o método dos Mínimos Quadrados em Dois Estágios (2SLS). Mais ainda, GMM permite o teste de validade dos instrumentos utilizados.

16 Uma variável alternativa, a EFENERG, seria a mediana do porcentual do valor adicionado da indústria em relação ao PIB de cada país, pois países mais industrializados tendem a demandar mais energia. Os testes discutidos aqui foram implementados com esta variável e os resultados permaneceram idênticos aos discutidos abaixo.

17 O número de países incluídos em cada teste variou de acordo com a disponibilidade de dados para as variáveis de controle (ver Apêndice 1).

18 Como explicado acima, os dados de investimento do PPI Database tem um caráter heterogêneo, refletindo, ao mesmo tempo, investimento realizado anualmente e comprometimento de investimento por longos períodos. Assim, em muitos casos, os valores anuais são intermitentes, o que dificulta a interpretação da análise de dados em painel e limita o número de países a serem incluídos nesses testes. Na análise de dados em cross-section, contudo, é possível calcular a mediana das observações existentes para cada variável entre 1990 e 2006 e interpretar aquele valor como o nível de comprometimento do setor privado no período. 
As variáveis de controle foram consideradas exógenas nos testes descritos abaixo, mas é possível argumentar que todas elas são endógenas. Por exemplo, o crescimento econômico pode levar a um maior nível de investimento em projetos de infra-estrutura com participação de setor privado e, ao mesmo tempo, contribuir para o aumento em RENDA, URBANA, LFIXASCEL e EFENERG, e para a redução em TXANALF. A estratégia de assumir a exogeneidade das variáveis de controle faz com que os seus coeficientes apresentem valores acima do correto e os coeficientes das variáveis de desenvolvimento institucional sejam menores do que deveriam. Ou seja, tratar as variáveis de controle como exógenas é uma estratégia "conservadora”, pois implica menor probabilidade de se encontrar um papel relevante para as variáveis de qualidade institucional (ver ACEMOGLU et al., 2003).

As equações estimadas possuem, portanto, o seguinte formato:

$\log \left(\right.$ PPI $\left._{\mathrm{S}}\right)=\alpha+\beta_{1}$ GOVERNANCA $+\beta_{2}$ FACINEG $+\beta_{3}$ INFMEDIA $+\beta_{4}$ RENDA $+\beta_{5}$ TXANALF

$+\beta_{6} \mathrm{URBANA}+\beta_{7} K_{S}+\varepsilon$

onde $\mathrm{PPI}_{\mathrm{S}}=\mathrm{PPI}$, PPITEL ou PPIEN, e $\mathrm{K}=$ EFENERG (quando $\mathrm{PPI}_{\mathrm{S}}=$ PPIEN) ou LFIXCEL (quando PPI $_{\mathrm{s}}=$ PPITEL). Os instrumentos incluem LGGER, LGFRAN e LGOUTROS, que possuem maior correlação com GOVENANCA e FACINEG, e as variáveis de controle.

\subsection{Análise em painel}

A análise de dados em painel, por sua vez, permite explorar a variação temporal dos dados e controlar resultados tendenciosos que emergem fruto de efeitos específicos não-observáveis de cada país. Assim, enquanto que, na análise em cross-section, é possível analisar como diferentes níveis de desenvolvimento institucional afetam o nível de investimento em projetos de infraestrutura com a participação do setor privado, na análise em painel, verifica-se como as variações nos indicadores de governança e de ambiente de negócios afetam o fluxo de investimentos para projetos de infra-estrutura com participação do setor privado entre os países. A amostra foi segmentada em oito períodos, pois os dados das variáveis de governança somente podem ser obtidos para 1996, 1998, 2000, 2002, 2003, 2004, 2005 e 2006.

Utilizou-se aqui também a metodologia econométrica GMM, pois, se as variáveis independentes incluídas forem endógenas, o modelo de efeitos fixos, normalmente utilizado em análise de dados em painel, leva a estimadores viesados. O objetivo é estimar a seguinte equação: ${ }^{19}$

$$
\mathrm{PPI}_{\mathrm{i}, \mathrm{t}}=\alpha+\beta_{1} W_{i, t}+\beta_{2} \mathrm{PPI}_{i, t-1}+\mu_{\mathrm{i}}+\lambda_{t}+\varepsilon_{i, t}
$$

onde $W=$ GOVERNANCA, INFMEDIA, RENDA e URBANA, $\mu$ representa a matriz de variáveis dummy para os países e $\lambda$ representa as variáveis dummy temporais.

19 Em função da falta de dados estatísticos, não foi possível implementar a análise de dados em painel levando em consideração o investimento setorial. Também pelo mesmo motivo, não foi possível incluir FACINEG e TXANALF como variáveis explicativas. 
Arellano e Bond (1991) sugerem empregar a primeira diferença da equação acima para eliminar os efeitos específicos associados a cada país e, para lidar com o problema de endogeneidade, utilizar variáveis explicativas em níveis, defasadas pelo menos dois períodos como instrumentos. De acordo com Blundell e Bond (1998) e Beck (2001), esse procedimento elimina a variação entre países presente nos dados estatísticos, uma desvantagem conceitual e que leva à imprecisão econométrica. Esses autores propõem como solução estimar-se um sistema de equações utilizando GMM (GMM-SIS). Neste sistema, equações em primeiras diferenças utilizam as variáveis defasadas em níveis como instrumentos, enquanto equações em níveis são estimadas utilizando variáveis defasadas em primeiras diferenças como instrumentos. Blundell e Bond (1998) defendem que, em simulações de Monte Carlo, este estimador em sistema reduz o viés em potencial e imprecisão associados com o uso do estimador em primeiras diferenças em amostras finitas.

Portanto, na análise de dados em painel, será estimado GMM-SIS, com as regressões "empilhadas" em diferenças e em níveis, com as seguintes condições de momento aplicadas à primeira e à segunda parte do sistema, respectivamente: $:^{20}$

$$
\begin{aligned}
& \mathrm{E}\left[\left(\varepsilon_{\mathrm{i}, \mathrm{t}}-\varepsilon_{i, t-1}\right) \mathrm{PPI}_{\mathrm{i}, \mathrm{t}-\mathrm{j}}\right]=0, j=2, \ldots, t-1 \text { e } t=3, \ldots, \mathrm{T} ; \\
& \left.\mathrm{E}\left[\left(\mathrm{PPI}_{i, t-j}-\mathrm{PPI}_{t-j-1}\right) \varepsilon_{\mathrm{i}, t}\right)\right]=0, j=2, \ldots, t-1 \text { e } t=3, \ldots, \mathrm{T} .
\end{aligned}
$$

A consistência do estimador GMM requer que $\varepsilon$ não exiba correlação serial e que os instrumentos sejam válidos. Serão utilizados dois testes padrões para confirmar a validade destas hipóteses (ver ARELLANO e BOND, 1991). O teste de correlação serial verificará se os erros em diferença são correlacionados em segunda ordem, já que a construção do modelo sugere que eles sejam correlacionados em primeira ordem. Se a hipótese nula de que não há correlação serial em segunda ordem for aceita, então o termo de erro original não é serialmente correlacionado e as condições de momento estão corretamente especificadas.

O teste de Sargan, por sua vez, confirmará se os instrumentos utilizados nos testes econométricos são representativos. A hipótese nula é que os instrumentos não são correlacionados com os resíduos e sua rejeição implica o não-atendimento das condições de ortogonalidade (o modelo não foi corretamente especificado). A estatística de Sargan segue uma distribuição $\chi^{(q-k)}$, onde $q$ é o número de coeficientes estimados e $k$ é o rank de instrumentos.

20 Condições de momento semelhantes se aplicam às variáveis explicativas, que são consideradas como potencialmente endógenas. Como os níveis defasados são utilizados como instrumentos na regressão em diferenças, somente a diferença mais recente é utilizada como instrumento na regressão em níveis, pois o uso de diferenças defasadas adicionais implicaria condições de momento redundantes (ver ARELLANO e BOVER, 1995). 


\section{RESUltados EMPÍRICOS}

De uma forma geral, constatou-se a importância da qualidade institucional na determinação do fluxo de recursos para projetos de infra-estrutura em países em desenvolvimento, tanto globalmente como para o setor de telecomunicações. Já para o setor de energia, os indicadores de governança e de ambiente para negócios não se mostraram representativos. A seguir, serão apresentados em detalhes os resultados das análises de dados em cross-section e em painel.

\subsection{Análise em cross-section}

A Tabela 4 apresenta os resultados dos testes econométricos implementados na amostra de dados em cross-section utilizando GMM. Nas análises de regressão, em que PPI representa a variável dependente, o coeficiente de GOVERNANCA é estatisticamente significante a um nível de $1 \%$, enquanto FACINEG e INFMEDIA não são relevantes (ver a primeira coluna da Tabela 4). GOVERNANCA também é economicamente significante. Considere, por exemplo, a Guatemala, país cujo investimento per capita em infra-estrutura com participação do setor privado de US $\$ 28,26$ representa a mediana da amostra. Um aumento de $10 \%$ na variável GOVERNANCA elevaria o investimento per capita em 28,1\%.

Análises de regressão incluindo individualmente cada indicador de desenvolvimento institucional revelaram que os coeficientes de CIVIL, CORRUP e GOVEFIC são positivos e estatisticamente significantes a um nível de 1\%, enquanto os coeficientes de LEIS e ESTPOL são positivos e estatisticamente significantes a um nível de 5\%. Esse resultado contrasta com aquele apresentado por Banerjee et al. (2006), cujos testes indicaram que um menor controle da corrupção estimularia o investimento em projetos de infra-estrutura com a participação do setor privado. ${ }^{21}$

Dentre as variáveis de controle, destacou-se URBANA, cujo coeficiente mostrou-se estatisticamente relevante a um nível de $1 \%$ na regressão em que PPI é a variável dependente. Quanto maior o grau de urbanização de um país, maior será a demanda por investimentos na provisão de serviços básicos de infra-estrutura, o que tende a viabilizar o equilíbrio econômico dos projetos, atraindo o investimento privado. A variável RENDA, por sua vez, é estatisticamente significante a um nível de $10 \%$, enquanto as demais variáveis de controle são irrelevantes estatisticamente.

21 Os resultados dos testes utilizando cada indicador de governança separadamente estão à disposição se requisitados. 
Tabela 4 - Análise de dados em cross-section

\begin{tabular}{|c|c|c|c|}
\hline & \multicolumn{3}{|c|}{ VARIÁVEL DEPENDENTE: } \\
\hline & PPI & PPITEL & PPIEN \\
\hline \multirow[t]{2}{*}{ C } & -3.067 & -2.380 & -1.965 \\
\hline & $(-1.476)$ & $(-1.050)$ & $(-0.494)$ \\
\hline \multirow[t]{2}{*}{ GOVERNANCA } & $0.034^{\star \star *}$ & $0.041^{\star * \star}$ & 0.011 \\
\hline & $(2.883)$ & (3.206) & $(0.479)$ \\
\hline \multirow[t]{2}{*}{ FACINEG } & 0.003 & 0.004 & 0.001 \\
\hline & $(0.419)$ & $(0.484)$ & $(0.107)$ \\
\hline \multirow[t]{2}{*}{ INFMEDIA } & -0.010 & -0.008 & 0.022 \\
\hline & $(-1.271)$ & $(-1.081)$ & $(1.160)$ \\
\hline \multirow[t]{2}{*}{ RENDA } & $0.403^{*}$ & 0.228 & 0.331 \\
\hline & $(1.817)$ & $(0.980)$ & $(0.660)$ \\
\hline \multirow[t]{2}{*}{ TXANALF } & 0.003 & -0.001 & 0.005 \\
\hline & $(0.552)$ & $(-0.166)$ & $(0.456)$ \\
\hline \multirow[t]{2}{*}{ URBANA } & $0.023^{\star \star *}$ & $0.019^{\star \star \star}$ & $0.028^{* \star *}$ \\
\hline & $(3.746)$ & $(2.513)$ & (2.529) \\
\hline \multirow[t]{2}{*}{ LFIXASCEL } & & 0.009 & \\
\hline & & $(0.566)$ & \\
\hline \multirow[t]{2}{*}{ EFENERG } & & & $-0.0004^{*}$ \\
\hline & & & $(-1.799)$ \\
\hline N. Obs. (n) & 82 & 71 & 53 \\
\hline Estatística J & 0.040 & 0.002 & 0.010 \\
\hline $\mathrm{n}^{*}$ Estatística J & 3.275 & 0.154 & 0.530 \\
\hline$\chi_{0,05}^{2}(1)$ & 3.841 & 3.841 & 3.841 \\
\hline
\end{tabular}

Notas: (i) Números em parêntesis representam as estatísticas $t$; ${ }^{*},{ }^{*} \mathrm{e}{ }^{* * *}$ indicam níveis de significância de 10\%, 5\% e 1\%; (ii) Matriz de Ponderação: os valores estimados quando utilizamos o GMM são robustos no que se refere a heterocedasticidade de fonte desconhecida; (iii) Instrumentos: LGGER, LGING, LGOUTROS, INFMEDIA e as variáveis de controle.

Quando PPITEL representou a variável dependente, o coeficiente de GOVERNANCA manteve-se positivo e estatisticamente significante a um nível de $1 \%$, enquanto os indicadores de ambiente para negócios não apresentaram relevância estatística (ver segunda coluna da Tabela 4). ${ }^{22}$ Considere, agora, Senegal, país cujo investimento per capita em telecomunicações de US $\$ 10,82$ representa a mediana da amostra. Um aumento de $10 \%$ em GOVERNANCA levaria a um incremento no investimento per capita em telecomunicações em 55,1\%, o que mostra que investidores privados no setor de telecomunicações são particularmente sensíveis ao grau de de-

22 Todos os indicadores de governança, quando incluídos individualmente nas análises de regressão, são positivos e estatisticamente relevantes. 
senvolvimento institucional de um país. Dentre as variáveis de controle, somente o coeficiente de URBANA apresentou significância estatística (nível de 1\%).

$\mathrm{Na}$ análise de regressão, em que PPIEN representa a variável dependente, os coeficientes dos indicadores de governança e de ambiente para negócios não apresentaram significância estatística (ver terceira coluna da Tabela 4). No que se refere às variáveis de controle, o coeficiente de URBANA é positivo e estatisticamente significante a um nível $1 \%$, enquanto o coeficiente de EFERNERG apresentou relevância estatística de 10\%. Ressalta-se, ainda, que o coeficiente de EFENERG é negativo, indicando que os investimentos em projetos de energia com a participação do setor privado tendem a concentrar-se em países onde existe um maior potencial de crescimento da demanda por energia.

\subsection{Análise de dados em painel}

A análise de dados em painel utilizou uma amostra com 58 países, com oito observações temporais para cada país (ver Tabela 5). Somente foi possível realizar a análise econométrica utilizando PPI como variável dependente, pois a desagregação setorial do investimento em infra-estrutura reduzia significativamente o número de países passíveis de inclusão na amostra. Ainda assim, os resultados apresentados a seguir confirmam que o desenvolvimento institucional é essencial para estimular a participação do setor privado em projetos de infra-estrutura.

O coeficiente de GOVERNANCA é positivo e estatisticamente significante a um nível de 1\%. A relevância econômica de GOVERNANCA é expressiva, como pode ser ilustrada com o seguinte exemplo. As Filipinas, cujo valor de PPI em 1996 de R $\$ 20,34$ representou a mediana da amostra, apresentou, neste mesmo ano, GOVERNANCA igual a 38,1. A análise econométrica indica que um aumento de $10 \%$ em GOVERNANCA implicaria uma elevação no investimento per capita em infra-estrutura com a participação do setor privado em 52,4\%.

Já o ambiente para negócios, aqui representado por INFMEDIA, também é estatisticamente significante a um nível de $1 \%$, mas com relevância econômica menos representativa. Ainda utilizando as Filipinas como exemplo, um aumento de $10 \%$ na taxa de inflação deste país levaria a uma redução no investimento per capita em infra-estrutura em apenas 6,6\%. Dentre as variáveis de controle, destacou-se apenas o valor defasado de PPI e URBANA, cujos coeficientes estimados foram positivos e estatisticamente significantes a um nível de $1 \%$ e $10 \%$, respectivamente. 


\section{Tabela 5 - Análise de Dados em Painel: GMM-SIS}

\begin{tabular}{lc}
\hline & VARIÁVEL DEPENDENTE: \\
\cline { 2 - 2 } C & $-3,640^{\star}$ \\
GOVERNANCA & $(-1,899)$ \\
& $0,048^{\star \star \star}$ \\
RENDA & $(3,988)$ \\
& 0,376 \\
URBANA & $(1,552)$ \\
& $0,019^{\star}$ \\
INFMEDIA & $(1,947)$ \\
PPI(-1) & $-0,003^{* \star \star}$ \\
& $(-2,417)$ \\
N. Obs. (n) & $0,231^{* \star \star}$ \\
Teste de Sargan (p-valor) & $(4,072)$ \\
Correlação Serial em 2a Ordem (p-valor) & 462 \\
\hline
\end{tabular}

Notas: (i) Números em parêntesis representam as estatísticas $t$; * ${ }^{* *} \mathrm{e}{ }^{* * *}$ indicam níveis de significância de $10 \%$, $5 \%$ e $1 \%$; (ii) Incluiu-se variáveis dummy temporais.

\subsection{Robustez dos resultados}

$\mathrm{Na}$ análise em cross-section, a estatística $J$ constitui o primeiro teste de solidez dos resultados obtidos com o uso da metodologia GMM (ver Tabela 3). Em todas as regressões, os valores desta estatística foram multiplicados pelo número de observações e comparados com o valor de tabela da distribuição $\chi 2$ com "graus de liberdade" iguais ao número de restrições sobreidentificadas. Em todos os casos, as variáveis instrumentais escolhidas foram consideradas informativas (significância estatística de 5\%).

A fim de verificar a robustez dos resultados obtidos na análise em cross-section, os testes foram conduzidos utilizando-se metodologias alternativas e excluindo outliers. De uma maneira geral, os indicadores de qualidade institucional mantêm-se estatisticamente significantes, independentemente da estratégia implementada.

Além de utilizar a metodologia GMM, todas as regressões com dados em cross-section foram implementadas fazendo uso de OLS e do método 2SLS (ver Apêndice 2). Os testes utilizando OLS mostram coeficientes de GOVERNANCA com menor nível de significância, mas 
os testes de Hausman rejeitaram a hipótese de que as estimativas utilizando OLS são consistentes nas regressões em que PPI e PPITEL são variáveis dependentes. ${ }^{23}$ Quando a metodologia utilizada foi 2SLS, os resultados obtidos foram idênticos àqueles descritos acima, com exceção da regressão em que PPITEL representou a variável dependente (aqui, o coeficiente de GOVERNANCA apresentou significância estatística de 10\%).

Como teste final de solidez dos resultados em cross-section, procurou-se identificar a presença de outliers a serem excluídos da análise de regressão, através da inspeção dos gráficos de dispersão e a aplicação do Teste de Grubbs. No Teste de Grubbs, identificou-se outliers somente para INFMEDIA (Uganda, Bielorrússia e Vanuatu) e para LFIXCEL (Croácia). Essas observações se posicionaram mais afastadas do restante da amostra e representam outliers significativos, com p $<0,05$, mas a sua exclusão da análise de regressão não modificou os resultados obtidos na seção 5.1 .

$\mathrm{Na}$ análise em painel, além de utilizar a metodologia GMM-SIS, também foi utilizado o modelo de painel com efeitos fixos e o estimador GMM em diferenças (GMM-DIF) proposto por Arellano e Bond (1991). Esses resultados, que estão apresentados no Apêndice 2, mostramse semelhantes aos delineados acima: o desenvolvimento institucional contribui de forma significativa para o envolvimento do setor privado em projetos de infra-estrutura em países em desenvolvimento.

Além disso, dois testes são relevantes para atestar a robustez dos resultados obtidos no modelo GMM-SIS (ver Tabela 4). Para verificar se o modelo foi corretamente especificado e se os instrumentos são válidos, utilizou-se o teste de Sargan das restrições sobreidentificadas. O valor-p encontrado excedeu 0,05 e, portanto, a hipótese de que os instrumentos são válidos é aceita a um nível de crítico de $5 \%$. O teste de correlação serial em segunda ordem, por sua vez, revelou que a hipótese nula de ausência correlação serial não pode ser rejeitada; ou seja, o termo de erro original não é serialmente correlacionado e as condições de momento estão corretamente especificadas.

\section{CONCLUSÃO}

A importância da qualidade institucional para o crescimento econômico e industrial e para a estabilidade macroeconômica tem sido objeto de estudo de uma vasta literatura. $\mathrm{O}$ presente trabalho fornece evidência empírica de que um maior desenvolvimento institucional estimula também o investimento em projetos de infra-estrutura com participação do setor privado.

Projetos de infra-estrutura envolvem investimentos elevados em ativos com longo prazo de maturação e com uso específico. Um ambiente institucional estável reduz, portanto, o risco do investimento, principalmente no que se refere à possibilidade de comportamento estratégico do

23 Os resultados dos testes de Hausman podem ser solicitados e obtidos da autora. 
governo e do setor privado, viabilizando, por conseguinte, uma maior eficiência operacional. Salienta-se, contudo, que, para o setor de energia, aspectos institucionais e o ambiente para negócios não se destacaram como relevantes, talvez em virtude da menor amostra de países que foi possível ser utilizada.

Dentre as variáveis de controle, o nível de concentração da população na zona urbana demonstrou ser relevante, tanto para o investimento em infra-estrutura de uma forma geral, quanto em nível setorial. Para investimentos em eletricidade e gás natural, sobressaíram-se a concentração da população em zonas urbanas e o nível de intensidade energética.

A análise de dados em painel, por sua vez, revelou que, além dos aspectos institucionais, a instabilidade macroeconômica inibe a participação do setor privado em projetos de infraestrutura em países em desenvolvimento.

O Brasil vem se destacando tanto em termos de número de projetos de infra-estrutura implementados com a participação do setor privado entre 1990 e 2006, quanto em termos do volume de recursos absorvidos. Entretanto, o País vinha experimentando um declínio nas atividades desde 1998, principalmente nos setores de eletricidade e telecomunicações, mas, desde 2004, é possível observar uma retomada dos investimentos, particularmente em projetos de eletricidade. Dentre os aspectos institucionais, as dificuldades na implementação e operacionalização de negócios constituem os principais entraves para um maior envolvimento do setor privado em infra-estrutura.

Diante dos resultados apresentados, é essencial que se delineiem medidas que fortaleçam o arcabouço institucional e o ambiente para negócios de um país. Em um contexto de restrições orçamentárias governamentais, o que é a norma em países em desenvolvimento, o estímulo à participação do setor privado pode viabilizar uma melhor eficiência operacional e eliminar gargalos na provisão de infra-estrutura. O nível e a qualidade dos serviços de infra-estrutura, por sua vez, afetam a produtividade, custos e competitividade de uma economia e sendo, portanto, essenciais para a promoção do crescimento econômico. 


\section{Apêndice 1 - Lista de países utilizados nos testes econométricos}

\begin{tabular}{|c|c|}
\hline & AMOSTRA TOTAL \\
\hline & $\begin{array}{l}\text { África do Sul, Argélia, Argentina, Azerbaijão, Bangladesh, Barbados, Belize, Bielorrússia, Bolívia, Brasil, Bulgária, } \\
\text { Burquina Faso, Burundi, Cabo Verde, Cazaquistão, Cisjordânia, Costa do Marfim, Camarões, Camboja, Chile, } \\
\text { China, Colômbia, Congo, Costa Rica, Croácia, Dominica, Egito, El Salvador, Equador, Eslováquia, Estônia, } \\
\text { Fiji, Filipinas, Gabão, Gana, Geórgia, Granada, Guatemala, Guiana, Guiné, Guiné Bissau, Honduras, Hungria, } \\
\text { lêmen, Ilha Maurício, Ilhas Seychelles, Índia, Indonésia, Irã, Jamaica, Jordão, Laos, Lesoto, Letônia, Lituânia, } \\
\text { Madagascar, Malásia, Malaui, Mali, Marrocos, México, Mianmar, Moçambique, Mongólia, Nepal, Nicarágua, } \\
\text { Nigéria, Omã, Panamá, Papua Nova Guiné, Paquistão, Paraguai, Peru, Polônia, Quênia, Quirgistão, República } \\
\text { Dominicana, República Checa, Romênia, Rússia, Senegal, Sérvia, Sri Lanka, Tailândia, Tajiquistão, Tanzânia, } \\
\text { Togo, Trinidad e Tobago, Tunísia, Turquia, Ucrânia, Uganda, Uruguai, Uzbequistão, Vanuatu, Venezuela, } \\
\text { Vietnam, Zâmbia e Zimbábue. }\end{array}$ \\
\hline & CROSS-SECTION \\
\hline PPI & $\begin{array}{l}\text { África do Sul, Argélia, Argentina, Azerbaijão, Bangladesh, Bielorrússia, Bolívia, Brasil, Bulgária, Burquina Faso, } \\
\text { Burundi, Cazaquistão, Cisjordânia, Costa do Marfim, Camarões, Camboja, Chile, China, Colômbia, Congo, Costa } \\
\text { Rica, Croácia, Egito, El Salvador, Equador, Estônia, Fiji, Filipinas, Gana, Guatemala, Guiana, Guiné, Honduras, } \\
\text { Hungria, lêmen, Ilha Maurício, Índia, Indonésia, Irã, Jamaica, Jordão, Laos, Lesoto, Letônia, Lituânia, Madagascar, } \\
\text { Malásia, Malaui, Mali, Marrocos, México, Moçambique, Mongólia, Nepal, Nicarágua, Nigéria, Omã, Panamá, Papua } \\
\text { Nova Guiné, Paquistão, Paraguai, Peru, Polônia, Quênia, República Dominicana, Romênia, Rússia, Senegal, Sri } \\
\text { Lanka, Tailândia, Tanzânia, Togo, Tunísia, Turquia, Ucrânia, Uganda, Uruguai, Uzbequistão, Venezuela, Vietnam, } \\
\text { Zâmbia e Zimbábue. }\end{array}$ \\
\hline PPITEL & $\begin{array}{l}\text { África do Sul, Argentina, Azerbaijão, Bangladesh, Bielorrússia, Bolívia, Brasil, Bulgária, Burundi, Cazaquistão, } \\
\text { Cisjordânia, Costa do Marfim, Camarões, Camboja, Chile, China, Colômbia, Congo, Costa Rica, Croácia, Egito, } \\
\text { El Salvador, Equador, Estônia, Fiji, Filipinas, Gana, Guatemala, Guiana, Guiné, Honduras, Hungria, lêmen, } \\
\text { Îndia, Indonésia, Irã, Jordão, Laos, Lesoto, Letônia, Lituânia, Madagascar, Malásia, Malaui, Marrocos, México, } \\
\text { Moçambique, Mongólia, Nicarágua, Nigéria, Panamá, Paquistão, Paraguai, Peru, Polônia, Quênia, República } \\
\text { Dominicana, Romênia, Rússia, Senegal, Sri Lanka, Tailândia, Tanzânia, Turquia, Ucrânia, Uganda, Uruguai, } \\
\text { Uzbequistão, Venezuela, Vietnam, Zâmbia e Zimbábue. }\end{array}$ \\
\hline \multirow[t]{2}{*}{ PPIEN } & $\begin{array}{l}\text { África do Sul, Argélia, Argentina, Bangladesh, Bielorrússia, Bolívia, Brasil, Cazaquistão, Costa do Marfim, Chile, } \\
\text { China, Colômbia, Congo, Costa Rica, Croácia, Egito, El Salvador, Equador, Estônia, Filipinas, Guatemala, } \\
\text { Honduras, Hungria, Índia, Indonésia, Jamaica, Letônia, Lituânia, Malásia, Marrocos, México, Nepal, Nicarágua, } \\
\text { Omã, Panamá, Paquistão, Peru, Polônia, Quênia, República Dominicana, Romênia, Rússia, Senegal, Sri Lanka, } \\
\text { Tailândia, Tanzânia, Tunísia, Turquia, Uruguai, Venezuela, Vietnam, Zâmbia e Zimbábue. }\end{array}$ \\
\hline & PAINEL \\
\hline PPI & $\begin{array}{l}\text { África do Sul, Argentina, Azerbaijão, Bangladesh, Bielorrússia, Bolívia, Brasil, Bulgária, Cazaquistão, Camboja, } \\
\text { Chile, China, Colômbia, Croácia, El Salvador, Equador, Eslováquia, Estônia, Fiji, Filipinas, Gana, Geórgia, } \\
\text { Guatemala, Honduras, Hungria, Îndia, Indonésia, Jordão, Laos, Lesoto, Letônia, Lituânia, Malásia, Marrocos, } \\
\text { México, Nicarágua, Nigéria, Panamá, Paquistão, Paraguai, Peru, Polônia, Quênia, Quirgistão, República Checa, } \\
\text { República Dominicana, Romênia, Rússia, Senegal, Sri Lanka, Tailândia, Tanzânia, Turquia, Ucrânia, Uganda, } \\
\text { Uzbequistão, Venezuela e Zâmbia. }\end{array}$ \\
\hline
\end{tabular}




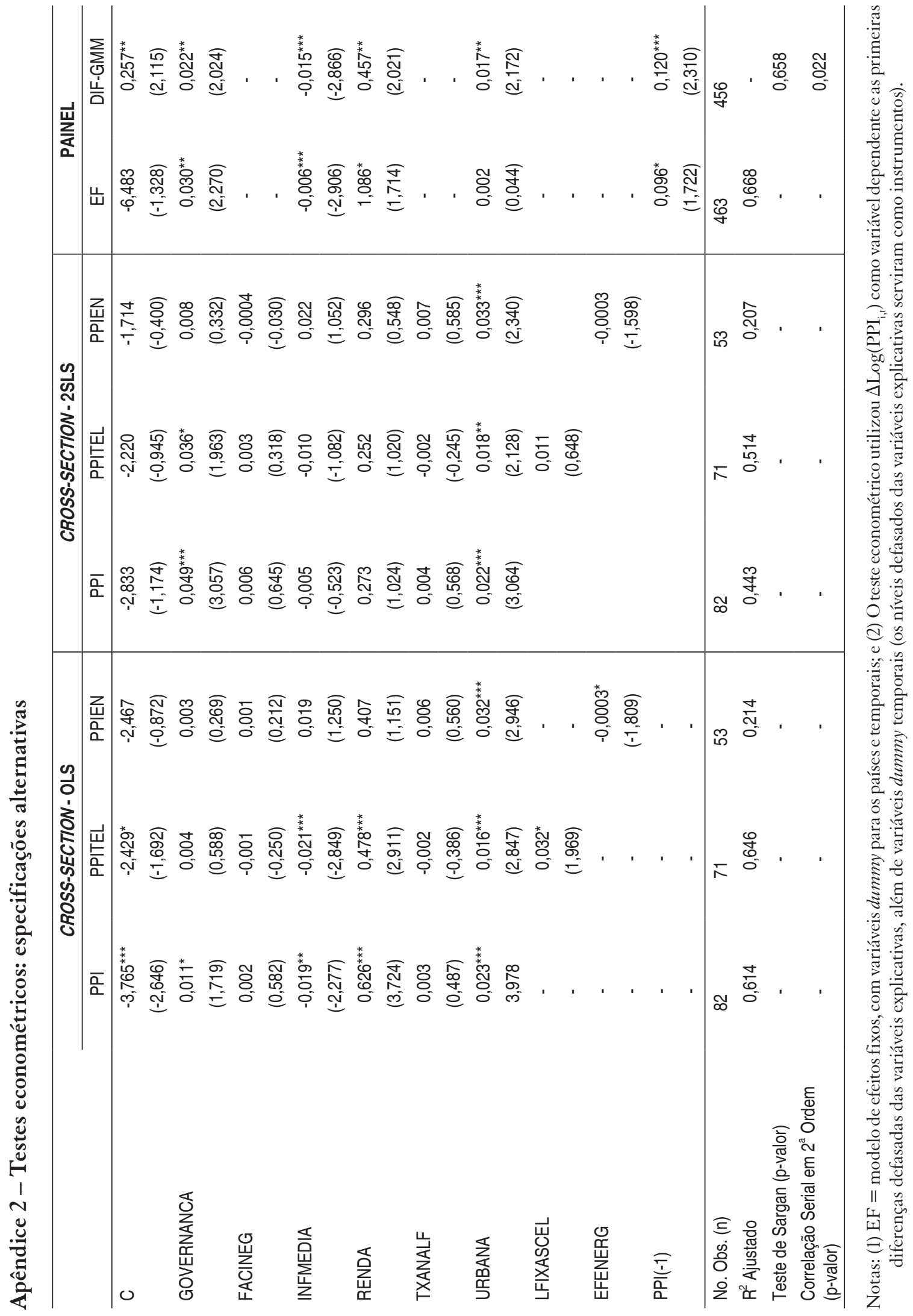




\section{REFERÊNCIAS}

ACEMOGLU, D.; JOHNSON, S.; ROBINSON, J.; THAICHAROEN, Y. Institutional causes, macroeconomic symptoms: volatility, crises and growth. Journal of Monetary Economics, v. 50, p. 49-123, 2003.

ANUATTI NETO, F.; BAROSSI FILHO, M.; CARVALHO, A. G.; MACEDO, R. Os efeitos da privatização sobre o desempenho econômico e financeiro das empresas privatizadas. Revista Brasileira de Economia, v. 59, n. 2, 2005, p. 151-175.

ARELLANO, M.; BOND, S. Some tests of specification for panel data: Monte Carlo evidence and an application to employment equations. Review of Economic Studies, v. 59, p. 277-297, 1991.

ARELLANO, M.; BOVER, O. Another look at the instrumental-variable estimation of error-components models. Journal of Econometrics, v. 68, 1995, p. 29-52.

BANCO MUNDIAL. PPI database. Washington: IBRD, 2006. Disponível em: < http://ppi.worldbank. org >. Acesso em: 27 set. 2006.

BANCO MUNDIAL. Governance indicators database. Washington: IBRD, 2007. Disponível em: < http:// info.worldbank.org/governance/wgi/index.asp>. Acesso em: 18 ago. 2008.

. World development indicators. Washington: IBRD, 2008. Disponível em: <http://publications. worldbank.org/WDI/>. Acesso em: 20 jul. 2008a.

BANCO MUNDIAL. Doing business database. Washington: IBRD, 2008. Disponível em: < http://www. doingbusiness.org/economyrankings $>$. Acesso em: 18 ago. 2008b.

BANERJEE, S.; OETZEL, J.; RANGANATHAN, R. Private provision of infrastructure in emerging markets: do institutions matter? Development Policy Review, v. 24, n. 2, p. 175-202, 2006.

BEATO, P.; VIVES, A. Private infrastructure investment at the subnational level: challenges in emerging economies. Inter-American Development Bank, 2003. (Working Paper, n. 10).

BECK, T. Financial development and international trade. Is there a link? In: World Bank Policy Research Working Paper, n. 2608, 2001.

BECK, T; DEMIRGUÇ-KUNT, A; LEVINE, R. Law and finance: why does legal origin matter? In: World Bank Policy Research Working Paper, n. 2904, 2002.

BERGARA, M.; HENISZ, W.; SPILLER, P. Political institutions e electric utility investment: a crossnation analysis. In: POWER Working Paper Series, n. 52, 1997.

BLUNDELL, R.; BOND, S. Initial conditions and moment restrictions in dynamic panel data models. Journal of Econometrics, v. 87, p. 115-43, 1998.

CALDERON, C.; SERVEN, L. The growth cost of latin america's infrastructure gap. In: EASTERLY, W.; SERVEN, L. (Ed.). Adjustment undermined? Infrastructure, public deficits and growth in Latin America, 1980-2000. Princeton, N.J.: Princeton University Press, 2003.

CIA. The world factbook. Washington: CIA, 2007.

CUBBIN, J.; STERN, J. Regulatory effectiveness and the empirical impact of variations in regulatory governance: electricity industry capacity and efficiency in developing countries. In: World Bank Policy Research Working Paper, n. 3535, 2005.

DJANKOV, S.; LA PORTA, R.; LOPEZ-DE-SILANEZ, F.; SHLEIFER, A. Legal structure and judicial efficiency: the lex mundi project. World Development Report, 2002.

EICHER, T.; PENALOSA, C.; TEKSOZ, U. How do Institutions lead some countries to produce so much more output than others. In: EICHER, T.; GARCÍA-PEÑALOSA, C. (Ed.). Institutions, development and economic growth. Cambridge: MIT Press, 2006. 
FUNDO MONETÁRIO INTERNACIONAL. World economic outlook database. Washington, DC: Fundo Monetário Internacional, 2007. Disponível em: < http://www.imf.org/external/pubs/ft/ weo/2007/01/data/weoselgr.aspx >. Acesso em: 18 ago. 2008.

GHURA, D.; GOODWIN, B. Determinants of private investment: a cross-regional empirical investigation. Applied Economies, v. 32, p.1819-1829, 2000.

GRIGORIAN, D.; MARTINEZ, A. Industrial growth and the quality of institutions - what do (transition) economies have to gain from the rule of law. In: World Bank Policy Research Working Paper, n. $2475,2000$.

GUASCH, J. L. Granting and renegotiating infrastructure concessions - doing it right. Washington, DC: World Bank, 2004.

HALL, R.; JONES, C. Why do some countries produce so much more output per worker than others? Quarterly Journal of Economics, v. 114, n. 1, p. 83-116, 1999.

HARRIS, J. C. Infraestructure projects - a review of cancelled private projects. Public Policy Journal, n. 252, 2003.

HENISZ, W. The institutional environment for infrastructure investment. Industrial and Corporate Change, v. 11, n. 2, p. 355-89, 2002.

IZAGUIRRE, A. Private telecom projects - private activity down 15 percent in 2003. Public Policy for the Private Sector, n. 288 , 2005.

. Private water projects - investment flows up by 36 percent in 2004. Public Policy for the Private Sector, n. 297, 2005a.

JENSEN, O.; BLANC-BRUDE, F. The handshake: why do governments and firms sign private sector participation deals? Evidence from the water and sanitation sector in developing countries. In: World Bank Policy Research Working Paper, n. 3937, 2006.

KAUFMANN, D.; KRAAY, A.; MASTRUZZI, M. Governance matters VII: aggregate and individual governance indicators 1996-2007. In: World Bank Policy Research Working Paper, n. 4654, 2008.

KIRKPATRIC, J.; PARKER, D.; ZHANG, Y. Foreign direct investment in infrastructure in developing countries: does regulation make a difference? Transnational Corporations, v. 15, n. 1, p. 143-71, 2006.

LA PORTA, R.; LOPEZ-DE-SILANEZ, F.; SHLEIFER, A.; VISHNY, R. Law and finance. Journal of Political Economy, v. 108, p. 1113-1155, 1998.

$---\overline{1999}$. The quality of government. Journal of Law, Economics and Organization, v. 15, p. 222-279,

PARGAL, S. Regulation and private sector investment in infrastructure - evidence from Latin America. In: World Bank Policy Research Working Paper, n. 3037, 2003.

REINIKKA, R.; SVENSSON, J. How inadequate provision of public infrastructure and services affect private investment. Policy Research Working Paper, n. 2262, 1999.

THE ECONOMIST. The Latinobarómetro poll - a warning for reformers. The Economist, 15 de novembro de 2007. Disponível em: < http://www.economist.com/world/americas/displaystory.cfm?story_ id=10136464>. Acesso em: 18 ago 2008. 